\title{
Ultra-Fine Fibers Produced by Laser-Electrospinning
}

\author{
Midori Takasaki ${ }^{* 1}, \mathrm{Hao} \mathrm{Fu}^{* 2}$, Kazuhiro Nakata ${ }^{* 2}$, Yutaka Ohkoshi ${ }^{* 2}$, and Toshihiro Hirai ${ }^{* 2}$ \\ ${ }^{*}$ Satellite Venture Business Laboratory, Shinshu University, 3-15-1, Tokida, Ueda, Nagano 386-8567, Japan \\ ${ }^{* 2}$ Faculty of Textile Science of Technology, Shinshu University, 3-15-1, Tokida, Ueda, Nagano 386-8567, \\ Japan
}

\begin{abstract}
We used a $\mathrm{CO}_{2}$ laser as a heat source to avoid thermodegradation in the melt-electrospinning process (termed "laser electrospinning" (LES)). Nylon 6, polypropylene, poly (ethylene terephthalate) and poly (L-lactide-co- $\varepsilon$ caprolactone) fiber webs were prepared by the LES. For Nylon 6 and poly (L-lactide-co- $\varepsilon$-caprolactone), fibers having average diameters of approximately $1 \mu \mathrm{m}$ and a coefficient of variation (CV) of no more than $20 \%$ were obtained. The effects of the applied voltage and laser power on the diameter of the PET fibers were investigated. The average diameter of the electrospun PET fibers decreased with a decrease in the applied voltage; however, using an applied voltage that was too low caused thermodegradation. The average diameter decreased with an increase in laser power. Above a certain laser power, however, shot particles and large deviations in the fiber diameter were observed.
\end{abstract}

(Received 25 September, 2007 ; Accepted 14 November, 2007)

\section{Introduction}

Ultra-fine fibers, which generally have diameters less than $10 \mu \mathrm{m}$, are used in filters, wiping clothes, artificial leather, etc., because of their large specific surface area and high flexibility. Ultra-fine fibers can be produced by the electrospinning process. [1-11] The electrospinning process generally involves generating a jet of polymer solution by applying an electric field; fibers are then formed by solidifying the liquid thread by evaporating the solvent, and they are collected on a grounded target. There is another electrospinning process that does not require a solvent [12-15]. It is termed meltelectrospinning and involves spinning the polymer in the molten state. Since it does not require a solvent, meltelectrospinning has the advantages of lower production cost and being more beneficial to the environment. It has, however, a weak point in that the molten polymer tends to degrade during the process. [14] To minimize this thermodegradation, a method for rapidly and uniformly heating the polymer by irradiating the polymer with a $\mathrm{CO}_{2}$ laser beam has been proposed. Ogata et al. prepared ultra-fine fibers of poly(ethylene-co-vinyl alcohol), poly (lactide) and poly(ethylene terephthalate) (PET) using this process. [16-18] They have also examined the effects of laser power and collector distance on the diameter of the fibers.

In this study, laser-heated melt-electrospinning (termed "laser electrospinning" (LES)) was used to produce ultra-fine fibers of Nylon 6, polypropylene (PP), PET and poly (L-lactide-co- $\varepsilon$-caprolactone) (P(LLA/CL)). These polymers were selected because of their industrial importance. In addition, the dependence of the applied voltage on the diameter of the obtained fiber was investigated for PET. The applied voltage contributes to the electrostatic force, so that changing the voltage will cause the drawing tension of molten polymer to vary. The applied voltage is thus one of the most important parameters when producing ultra-fine fibers by LES.

\section{Experimental}

\subsection{Materials}

Monofilaments of PET (average diameter : $196 \mu \mathrm{m}$ ), Nylon 6 (average diameter: $188 \mu \mathrm{m}$ ), PP (average diameter : $190 \mu \mathrm{m})$, and P(LLA/CL) (average diameter : $193 \mu \mathrm{m})$ were used to produce ultra-fine fibers.

\subsection{Laser electrospinning process}

A schematic diagram of the LES system used is shown in Fig. 1. It was composed of a laser irradiation system that had a $\mathrm{CO}_{2}$ laser (PIN-30R, Onizuka Glass Co., Ltd.) and an electrospinning system (NEU-010, Katotech Co., Ltd.) that consisted of a fiber feed roller, a nozzle for feeding the fiber, a copper plate for collecting the spun fiber, and an electric power source for drawing the laserheated molten polymer fibers. The sample fiber was fed at a constant velocity by the feed roller and was ejected from a nozzle, which had an internal diameter of about 
Table 1 Laser electrospinning conditions and electrospun fiber diameters.

\begin{tabular}{|c|c|c|c|c|c|c|c|c|}
\hline \multirow[b]{2}{*}{ No. } & \multirow[b]{2}{*}{ Polymer } & \multicolumn{5}{|c|}{ LES conditions } & \multicolumn{2}{|c|}{ Diameter } \\
\hline & & $\begin{array}{l}\text { Initial fiber } \\
\text { diameter } \\
(\mu \mathrm{m})\end{array}$ & $\begin{array}{l}\text { Feed speed } \\
(\mathrm{m} / \mathrm{min})\end{array}$ & $d(\mathrm{~mm})$ & $\begin{array}{c}\text { Applied } \\
\text { voltage } \\
(\mathrm{kV})\end{array}$ & $\begin{array}{c}\text { Laser } \\
\text { power } \\
\text { (W) }\end{array}$ & $\begin{array}{c}\text { Average } \\
(\mu \mathrm{m})\end{array}$ & $\begin{array}{l}\mathrm{CV} \\
(\%)\end{array}$ \\
\hline 1 & & & & & 15 & 20 & 1 & 20 \\
\hline 2 & Nylon 6 & 188 & 0.04 & 2 & 15 & 15 & 4 & 21 \\
\hline 3 & & & & & 20 & 14 & 3 & 14 \\
\hline 4 & & & 0.04 & & & 7 & 2 & 7 \\
\hline 5 & P(LLA/CL) & 193 & 0.02 & 2 & 20 & 20 & 2 & 14 \\
\hline 6 & & & 0.04 & & & 20 & 1 & 16 \\
\hline 7 & PP & 190 & 0.04 & 5 & 20 & 5 & 38 & 13 \\
\hline 8 & & & & & 10 & & 4 & 95 \\
\hline 9 & PET & 196 & 0.04 & 2 & 15 & 5 & 51 & 7 \\
\hline 10 & & & & & 20 & & 81 & 5 \\
\hline 11 & & & & & 25 & & 102 & 7 \\
\hline 12 & & & & & & 4 & 74 & 20 \\
\hline 13 & PET & 196 & 0.04 & 2 & 15 & 6 & 10 & 86 \\
\hline 14 & & & & & & 7 & 4 & 86 \\
\hline
\end{tabular}

$1.1 \mathrm{~mm}$ and a length of $15 \mathrm{~mm}$. A high voltage was applied between the nozzle and a copper collector plate. The $\mathrm{CO}_{2}$ laser beam was about $2 \mathrm{~mm}$ wide, and the distance from the nozzle tip to the collector plate was 50 $\mathrm{mm}$. The other spinning conditions are summarized in Table 1 .

\subsection{Characterization of laser-electrospun fibers}

The electrospun fibers were observed using a scanning electron microscope (S-2380 N, Hitachi HighTechnologies Corp.).

\section{Results and discussion}

The average diameter of the spun fibers and its coefficient of variation (CV) were obtained from the SEM images and are listed in Table 1. All the polymers used in this experiment could be spun. Nylon 6 and P(LLA/CL)

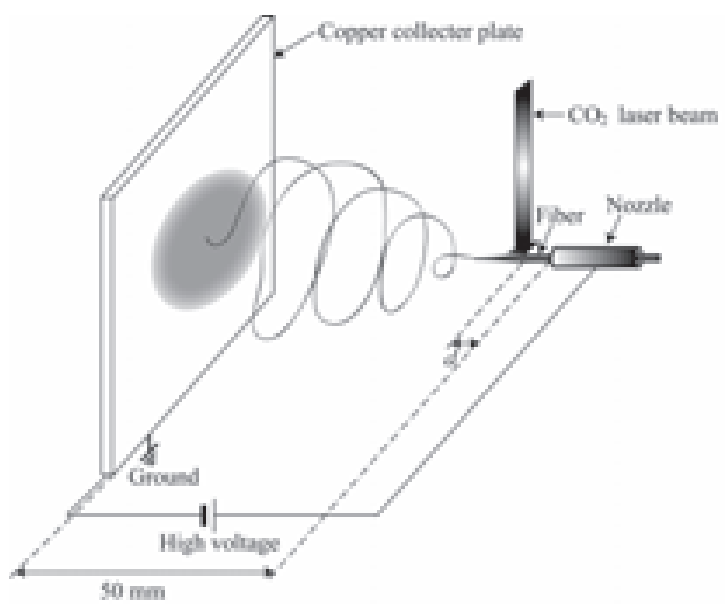

Fig. 1 Schematic diagram of laser electrospinning system. fibers having average diameters of $1 \mu \mathrm{m}$ (CV of about $20 \%$ ) could be produced by the LES process (see Fig. 2). Although ultra-fine PET fibers having an average diameter of $4 \mu \mathrm{m}$ could be obtained, the $\mathrm{CV}$ of the diameter was greater than $85 \%$. Ultra-fine fibers of PP could not be produced.

The effect of the applied voltage and laser power on the diameter of the PET fibers is shown in Fig. 3. As shown above, ultra-fine PET fiber could be produced at the applied voltage of $10 \mathrm{kV}$. If the applied voltage was lower than $10 \mathrm{kV}$, PET fibers were completely degraded. Meanwhile with the increase in applied voltage over 10 $\mathrm{kV}$, although the deviation in diameter and the amount of shot particles were decreased, the average fiber diameter increased. We presume high temperature and quite low melt viscosity lead the finer fiber despite of low electrostatic force at $10 \mathrm{kV}$. It is because the lower applied voltage leads lower drawing tension, and resultant longer heating time in laser irradiation region causes higher temperature and drastic decrease in the viscosity of melt. Too high temperature of melt causes thermodegradation. On the other hand, with the increase of laser power, the diameter decreased whereas the deviation of the diameter and the amount of shot particles increased
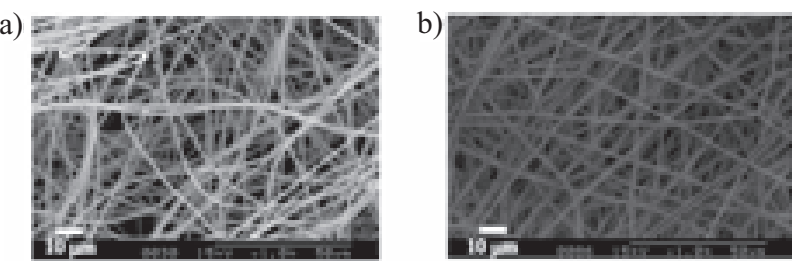

Fig. 2 SEM images of Nylon 6 and P(LLA/CL) electrospun fibers. The spinning conditions are those of (a) No. 1 and (b) No. 6 shown in Table 1. 

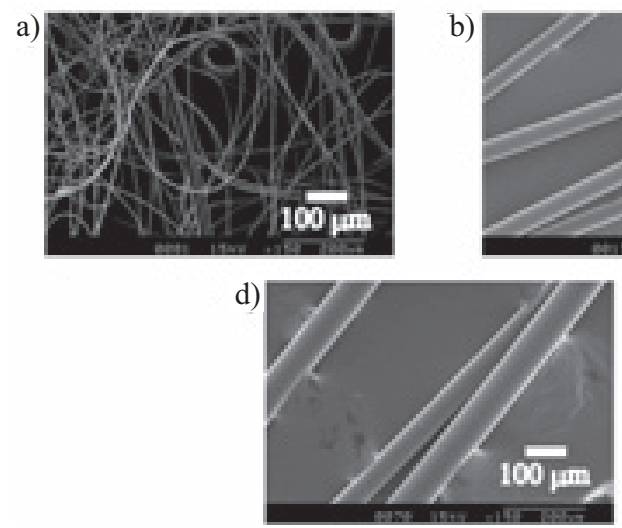
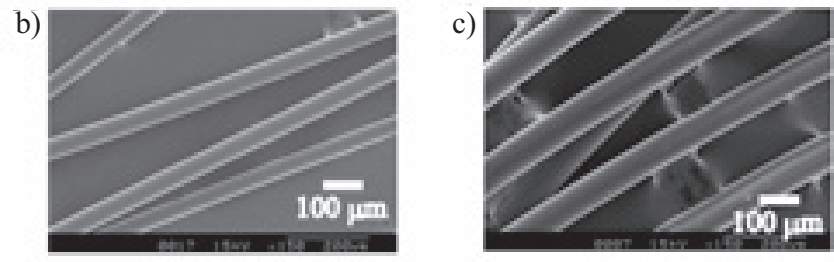

e)

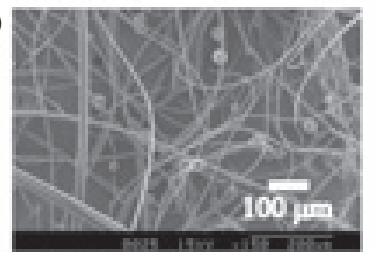

Fig. 3 Applied voltage and laser power dependence for PET fibers. The spinning conditions are those of (a) No. 8, (b) No. 9, (c) No. 10, (d) No. 12 and (e) No. 13 of Table 1.

for the laser power above $6 \mathrm{~W}$. These results can be also explained by the higher temperature for higher laser power. These results clarify that the applied voltage and laser power are the key factors for producing ultra-fine fibers by LES.

\section{Conclusions}

We succeeded in preparing fiber webs of Nylon 6, $\mathrm{PP}, \mathrm{PET}$ and $\mathrm{P}(\mathrm{LLA} / \mathrm{CL})$ by melt-electrospinning using laser irradiation to heat the polymer. In particular, for Nylon 6 and P(LLA/CL) we were able to produce a web of ultra-fine fibers having average diameters of about $1 \mu \mathrm{m}$ and a CV of less than $20 \%$. We investigated the effect of applied voltage and laser power on the diameter of the electrospun PET fibers. We found that the average diameter of the PET fibers was reduced by decreasing the applied voltage, while using an applied voltage that is too low resulted in thermodegradation of the fibers. The diameter was found to decrease with an increase in the laser power, while the PET fibers web revealed a large deviation in diameter and in shot particles above a certain laser power.

\section{Acknowledgements}

The authors express their sincere thanks to Mr. K. Morie and Mr. S. Kinugawa for helpful experimental support. The authors would like to acknowledge the support of the Collaborative Innovation Center for Nanotech FIBER (nanoFIC) supported by the Japan Science and Technology Agency.

\section{References}

1. G. Taylor, Proc $R$ Soc London, Ser A, 313, 453
(1969).

2. A. F. Spivak, Y. A. Dzenis, D. H. Reneker, Mech. Res. Comm., 27, 37 (2000).

3. D. H. Reneker, A. L. Yarin, H. Fong, S. Koombhongse, J. App. Phys., 87, 4531 (2000).

4. A. L. Yarin, S. Koombhongse, D. H. Reneker, J. Appl. Phys., 90, 4836 (2001).

5. M. G. McKee, J. M. Layman, M. P. Cashion, T. E. Long, Science, 311, 353 (2006).

6. F. Ko, Y. Gogotsi, A. Ali, N. Naguib, H. H. Ye, G. L. Yang, C. Li, P. Willis, Adv. Mater., 15, 1161 (2003).

7. Z. C. Sun, E. Zussman, A. L. Yarin, J. H. Wendorff, A. Greiner, Adv. Mater., 15, 1929 (2003).

8. S. R. Givens, K. H. Gardner, J. F. Rabolt, D. B. Chase, Macromolecules, 40, 608 (2007).

9. M. L. Ma, Y. Mao, M. Gupta, K. K. Gleason, G. C. Rutledge, Macromolecules, 38, 9742 (2005).

10. M. Wang, H. J. Jin, D. L. Kaplan, G. C. Rutledge, Macromolecules, 37, 6856 (2004).

11. M. G. McKee, G. L. Wilkes, R. H. Colby, T. E. Long, Macromolecules, 37, 1760 (2004).

12. L. Larrondo, R. Manley, J. St, J Polym. Sci. : Polym. Phys., 19, 909 (1981).

13. J. Lyons, C. Li, F. Ko, Polymer, 45, 7597 (2004).

14. J. S. Kim, D. S. Lee, Polym. J., 32, 616 (2000).

15. R. Rangkupan, D. Reneker, http : //www.tx. ncsu. edu/jtatm/volume1specialissue/posters/ posters_part 1.pdf

16. N. Ogata, G. Lu, T. Iwata, S. Yamaguchi, K. Nakane, T. Ogihara, J. Appl. Polym. Sci., 104, 1368 (2007).

17. N. Ogata, S. Yamaguchi, N. Shimada, G. Lu, T. Iwata, K. Nakane, T. Ogihara, J. Appl. Polym. Sci., 104, 1640 (2007).

18. N. Shimada, N. Ogata, S.Yamaguchi, K. Nakane, T, Ogihara, Extended Abstracts of The 36th Textile Research Symposium, 10 (2007). 